\title{
CAD Design of Human Male Body for Mass- Inertial Characteristics Studies
}

\author{
Gergana Nikolova, ${ }^{*}$, Vladimir Kotev, and Daniel Dantchev \\ Institute of Mechanics, Bulgarian Academy of Sciences, Acad. G. Bonchev Str., Building 4, Sofia 1113, \\ Bulgaria
}

\begin{abstract}
The aim of the present research is to present a 16 -segmental biomechanical model of the Bulgarian male to determine the mass-inertial characteristics of the body of the Bulgarian male based on parameters available in the literature and its 3D generation within SolidWorks software. The motivation of the research is to support mainly sport, rehabilitation, wearable robots and furniture design users. The proposed CAD model of the human body of men is verified against the analytical results from our previous investigation, as well as through comparison with data available in the provided references. In this paper we model two basic human body positions: standing position and sitting with thighs elevated. The comparison performed between our model results and data reported in literature gives us confidence that this model can be reliably used to calculate the mass-inertial characteristics of male body at any postures of the body that is of interest. Therefore, our model can be used to obtain data for positions which the human body has to take in everyday live, in sport, leisure, including space exploration, for investigating criminology cases body fall, car crash, etc. The model is suitable for performing computer simulation in robotics, medicine, sport and other areas.
\end{abstract}

\section{Introduction}

The human motion is a topic of analysis since ancient times. To make this analysis scientifically sound one obviously needs the knowledge of the geometric and mass-inertial characteristics of the body as total, as well as of the different human body segments. In modern times such studies were related to topics like investigations oriented in the design of air or space transport systems - they have been conducted in the 70-s on elderly male cadavers [1]. In the same period the anthropometric measurements and data for moments of inertia and centers of gravity have been also obtained for living male individuals of the Air Force population. They were collected for the inertial parameters about three mutually perpendicular axes for various body positions $[2,3]$. In the early 21 st century the same positions were examined in the scale-up study, see [4]. In paper [5] authors present a study for modeling and simulation of human body by considering the skeleton's bones. Body segment inertial parameters (BSIPs) are obtained by cameras and motion analysis methods

\footnotetext{
*Corresponding author: gergana1973@gmail.com
} 
[6]. Authors computed individual BSIPs from scan images. Body segment parameters of young Chinese men are determined with magnetic resonance imaging in Ref. [7]. Mass, center of mass, and moment of inertia estimates for infant limb segments are studied in [8]. The analysis of lower limb movements has been well established in biomechanics research and clinical applications for a long time. For these studies, powerful and very advanced tools have been developed to measure movement parameters and reaction forces. The main focus of interest aims towards gait movements where the understanding of the basic concepts is supported by numerous models. Definitions of physiological ranges and detection of pathological changes in movements open an increasingly valuable clinical field of application. If, however, the primary function of the upper extremities as highly variable and adaptive organ for manipulating tasks is the subject of interest, the situation becomes considerably more complex [9]. It is necessarily to determine mass-inertial characteristics in order to study human movement and its mechanics [10].

During the past decade, a lot of research of wearable robotics has been done $[11,12]$. In order to design and develop exoskeletons and wearable robots it is again necessarily to determine mass-inertial characteristics of each user. There is a relationship between the wearable devices and the dimensions of mechanical construction which are specific for each individual and thus the power of the motors (electric or pneumatic) is different. Generally, in order to study the human dynamics of different postures, one unavoidably has to determine mass inertial characteristics of human body in different positions. These characteristics are, obviously, individual and depend on the size of body segments and their mass [5-12].

In the current article we propose an approach to the problem based on a mathematical model realized in a suitable computer media. The design of 3D model of the human body requires knowledge of anthropometry and biomechanics. Moreover, one should successively solve specific problems, related to: i) appropriate body decomposition; ii) choice of necessary anthropometric points; iii) organization of data that give the geometrical and mass-inertial characteristics of the human body and its segments; iv) model generation within a CAD system (e.g. SolidWorks); v) verification of the model via analytical results. The $3 \mathrm{D}$ model should enable to perform fast individualization using a small range of parameters that could be easily determined.

In the current study, we suggest such a model and provide data for the mass-inertial parameters of the human body in two basic positions, and compare our results with those available from the literature. In order to do that we are going to use a realization of the model within a CAD system - Solid Works.

\section{Model and method}

We use a mathematical model of the human body described in details in [13]. There this model has been used to determine the mass inertial parameters of the different segments of the body. Here we only present some basic facts for the model used in the current study see Fig. 1.

The model consists of 16 segments representing: head + neck, upper, middle and lower part of torso, thigh, shank, foot, upper arm, lower arm and hand, assumed to be relatively simple geometrical bodies. We assume full body symmetry with respect to the sagittal plane. The geometrical data needed is taken from a detailed anthropological investigation of the Bulgarian population [14]. A total of 2435 males were measured. We take the average values and design a model, which represents the so defined average Bulgarian male. After determining the mass inertial parameters of the segments, one can also study the corresponding characteristics of the total body assuming the body to be in a given position of interest. 

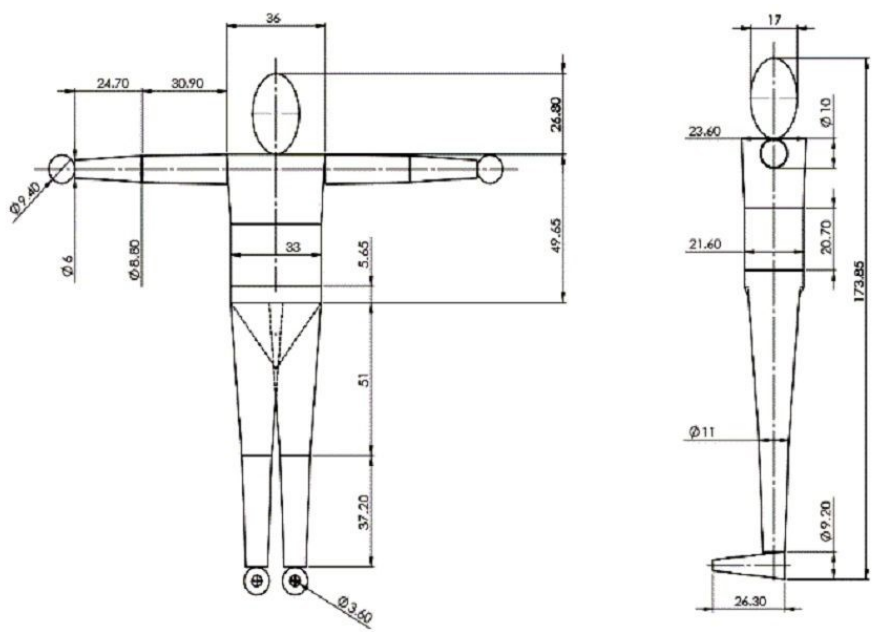

Fig. 1. 16-segemental model of the human body and the corresponding dimensions.

In order to achieve this goal, we have performed a realization of the model in CAD system - SolidWorks. We have verified the computer realization by comparing the results it delivers for the mass-inertial parameters of the segments of the body with those reported in [13]. The basic positions of the body have been classified long ago in the literature - see, e.g., $[1,2,3]$. One normally considers eight principal body positions. Here, we will present data for two of these positions: the so-called "standing position" and the so-called "sitting, thighs elevated position" - see Fig. 2.
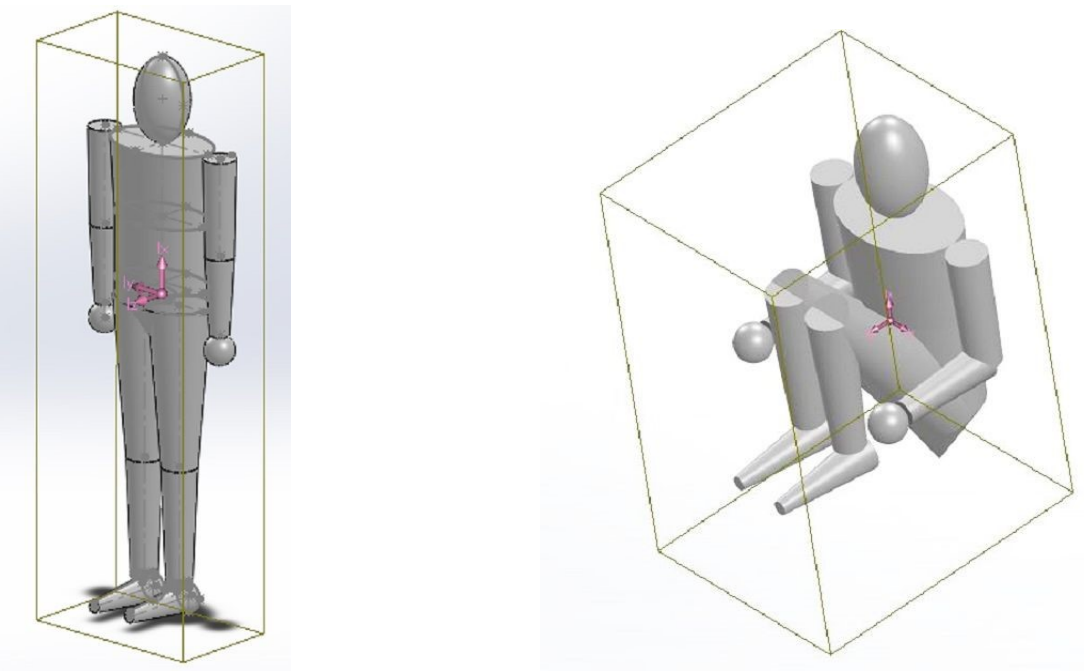

Fig. 2. Standing position (left); Sitting, thighs elevated position (right)

\section{Determination of mass-inertial characteristics using SolidWorks media}

The 3D CAD Design software SolidWorks, is used to generate the model.

The computer-generated model is verified by comparing its results with those reported in [13] for the different segments of the body. The program procreates segment-by-segment 
data about volume, mass, center of mass and moments of inertia. That gives us assurance that this model could be used to calculate these characteristics at different body positions of the body. The data for the mass-inertial parameters of the human body in positions shown in Fig. 2 are presented in Tables 1 and 2. Table 1 contains the data for the so-called standing position, Table 2 - data for the principal moments of inertia of the body in socalled sitting, thighs elevated position as well as the coordinates of whole center of mass of the body.

Table 1. Standing position.

\begin{tabular}{|c|c|c|c|c|c|c|c|}
\hline & \multicolumn{2}{|c|}{$\begin{array}{l}\text { Ref. } \\
{[4]}\end{array}$} & \multirow[t]{2}{*}{$\begin{array}{l}\text { Ref. } \\
\text { [1] }\end{array}$} & \multirow[t]{2}{*}{$\begin{array}{l}\text { Ref. } \\
{[2]}\end{array}$} & \multicolumn{2}{|c|}{$\begin{array}{l}\text { Ref. } \\
{[3]}\end{array}$} & \multirow[t]{2}{*}{$\begin{array}{l}\text { Our } \\
\text { data }\end{array}$} \\
\hline & $50 \%$ & $95 \%$ & & & $50 \%$ & $95 \%$ & \\
\hline $\mathrm{IXx}\left[\mathrm{kg} \cdot \mathrm{cm}^{2} \mathrm{x} 10^{3}\right]$ & 14.4 & 18.5 & 17.2 & 12.7 & 9.1 & 14.1 & 9.7 \\
\hline IYY $\left[\mathrm{kg} . \mathrm{cm}^{2} \times 10^{3}\right]$ & 129.2 & 163.4 & 118.9 & 116.0 & 116.2 & 161.9 & 105.3 \\
\hline Izz $\left[\mathrm{kg} . \mathrm{cm}^{2} \times 10^{3}\right]$ & 144.5 & 182.3 & 134.0 & 129.5 & 122.3 & 171.1 & 112.0 \\
\hline $\begin{array}{l}\text { Center of mass } \\
{[\mathrm{cm}]}\end{array}$ & 80.2 & 84.7 & 72.3 & 78.7 & 80.0 & 83.8 & 74.6 \\
\hline Total mass [kg] & 82.2 & 98.5 & 65.2 & 75.5 & 73.4 & 90.9 & 72.5 \\
\hline Height $[\mathrm{cm}]$ & 179.9 & 190.1 & 172.1 & 176.3 & 175.5 & 185.7 & 171.5 \\
\hline
\end{tabular}

Following the definition of [3] in the "standing position" the individual stands erect with head oriented in the so-called Frankfort plane and with arms hanging naturally at the sides - see Fig. 2 (left). In the "sitting, thighs elevated position" thighs and forearms are placed parallel to the $\mathrm{X}$-axis, the upper arms, shanks and spine are parallel to the $\mathrm{X}$-axis; the soles are parallel to $\mathrm{X}-\mathrm{Y}$ plane; wrist axes are parallel to Z-axis, and the head lies in Frankfort plane - see Fig. 2 (right).

Table 2. Moments of inertia in standing position and the whole body center of mass location in sitting, thighs elevated position.

\begin{tabular}{|l|c|c|c|c|}
\hline Characteristics & \multicolumn{2}{|c|}{$\begin{array}{c}\text { Ref. } \\
{[\mathbf{4}]}\end{array}$} & $\begin{array}{c}\text { Ref. } \\
{[\mathbf{1}]}\end{array}$ & $\begin{array}{c}\text { Our } \\
\text { data }\end{array}$ \\
\hline & $50 \%$ & $95 \%$ & & \\
\hline IXx $\left[\mathrm{kg} \cdot \mathrm{cm}^{2} \times 10^{3}\right]$ & 13.1 & 15.2 & 17.9 & 18.3 \\
\hline IYY $\left[\mathrm{kg} \cdot \mathrm{cm}^{2} \times 10^{3}\right]$ & 48.6 & 55.8 & 42.8 & 33.3 \\
\hline IZZ $\left[\mathrm{kg} \cdot \mathrm{cm}^{2} \times 10^{3}\right]$ & 48.7 & 59.8 & 44.0 & 31.4 \\
\hline L (x) & 59.4 & 61.5 & 58.7 & 53.6 \\
\hline L (y) & 0 & 0 & 0 & 0 \\
\hline L (z) & 9.7 & 10.5 & 11.7 & 7.3 \\
\hline
\end{tabular}


The coordinate frame used is with axes which coincide with the approximate body axes: the sagittal (y), the frontal (z) and the longitudinal (x) ones. The Tables contain also data from the available literature found by using other methods. The coordinate system for the results reported, as well as the units used there, have been converted to the ones used in present investigation. The $50 \%$ and $95 \%$ marks mean that the corresponding percent of measured data are below the value reported.

The analysis shows a reasonably good agreement between our results and those previously reported in the literature.

\section{Conclusion}

We proposed a 16-segment model of the human body of the average Bulgarian male and its 3D model realization in SolidWorks environment. Data for the mass-inertial characteristics of the body in two of its basic positions are obtained and compared with those reported in the literature. The comparison between our model results and data reported in literature - see Tables 2 and 3 - gives us confidence that this model could be used to calculate the mass inertial characteristics at any specific posture of the male body.

The motivation of the research is to support mainly sport, rehabilitation, wearable robots and ergonomics (furniture design users). The model may be applied also in other areas such as simulation of the human behavior in space, medicine (orthopedics, orthotics and prosthetics design), criminology, etc.

To reduce the differences between the results obtained and those available in the literature, we plan to improve segment modeling by using geometric bodies closer to the real shape of the human body segments. For that aim, one needs to collect data for additional anthropometric parameters. This is currently underway. Naturally, for the new set of geometric bodies one will need again to derive analytical expressions for their massinertial parameters and to compare with those obtained through the corresponding realization of the modified model within a suitable CAD/CAM system.

The financial support by the Bulgarian National Science Fund: Contract DN-07/5 "Study of anthropometric and mass-inertial characteristics of the Bulgarian men and women via mathematical models of the human body" is gratefully acknowledged.

\section{References}

1. C. E. Clauser, J. T. McConville, J. W. Young, Weight, volume, and center of mass of segments of the human body, TR AMRL-TR-69-70, Ohio, (1969).

2. W. R. Santschi, J. DuBois, C. Omoto, Moments of Inertia and Centers of Gravity of the Living Human Body, AMRL TR 63-36. Ohio, (1963).

3. E. P. Hanavan, A mathematical model of the human body, AMRL-TR-64-102, Ohio, (1964).

4. NASA-STD-3000, The man_system integration standards, Anthropometry and biomechanics at: https://msis.jsc.nasa.gov/sections/section03.htm\#3.2.1.

5. D. Andreescu, Fl. Ionescu, H. Riehle, Modelling and Simulation of Human Body by Considering the Skeleton's Bones, (IASTED Intern Confer BioMechanics August 1618 2007, Honolulu Hawaii, USA, 2007).

6. M. Rossi, A. Lyttle, N. Benjanuvatra, B. Blanksby, J Sports Sciences Med., 12, 4 (2013).

7. Ho Wh., S. Ty, L. Cc, Y. Cheng, Med Sci Sports Exerc. 45, 9 (2013). 
8. K. Schneider, R. Zernicke, J Biomech., 25, 2 (1992).

9. G. Rau, C. Disselhorst-Klug, R. Schmidt, J Biomech., 33, 10 (2000).

10. A. Tözeren, Human Body Dynamics Classical Mechanics and Human Movement (Springer, 1999).

11. J. Pons, Wearable Robots: Biomechatronic Exoskeletons (John Wiley and sons, Ltd, England, 2008).

12. W. Huo, S. Mohammed, J. Moreno, Y. Amirat, IEEE Systems Journal, 10, 3 (2016).

13. G. Nikolova, Y. Toshev, J Biomech., 40, 16 (2007).

14. Y. Yordanov et al. Anthropology of the Bulgarian population at the end of the 20th century (30-40 years old persons) (Prof. Marin Drinov Academic Publishing House, Sofia, Bulgaria, 2006). 